\title{
Applications and Some Recent Developments of Nucleonic Control Systems in Japan ${ }^{\dagger, *}$
}

\author{
Hiroshi Tominaga \\ Institute of Radiation Measurements \\ Shirakata Shirane, Tokai-mura, \\ Ibaraki-Pref. 319-11, Japan
}

\begin{abstract}
Key Words : nucleonic control system, radioisotope gauge, analyzer, industrial application, recent development
\end{abstract}

\section{Introduction}

The word "Nucleonic Control System" (abbreviated as NCS) seems to have the meaning of hardware and software capable of measuring some physical quantities by means of nuclear techniques and controlling those quantities in some way. It includes measuring equipment used on line in industrial processes with feedback control, as well as instruments, analyzers, etc. used off line without any direct control in industry and its environment. NCS therefore nearly corresponds to radiation measurement application in instrumentation. Description in this paper will be provided in such a broad sense of the word.

The state of the difffusion of NCSs in Japan can be seen in "Statistics on the Use of Radiation in Japan" published annually by the Japan Radioisotope Association. As shown in Fig. 1, most of nucleonic gauges and apparatus spread remarka-

†日本における RI 放射線応用計測機器の利用之最近 の開発例。富永 洋 : (盺)放射線計測協会, 319-11 茨城県那珂郡東海村白方白根。

* A revised paper originally presented at the IAEA Advisory Group Meeting on Current Status, Developments and Applications of Nucleonic Control Systems in Industry, held at the Nuclear Energy Unit, PUSPUTI, Bangi in Malaysia, June 3-7, 1991. bly in industry in the period from about the middle of the 1960's to the first half of the 1970's along with a high economic growth with which Japan encountered in this period ${ }^{1)}$.

The rapid increase in the number of sulfur meters and gaschromatograph apparatus with an electron capture detector (ECD) in that period is particularly worthy of remark, since it is attributed to the necessity of control of the environmental pollution caused by the high economic growth.

The rapid spread of all the NCSs stopped with the termination of the high economic growth at the middle of the 1970's. Some kinds of the gauges and apparatus in the past 15 years are nearly in saturation or gradually decreasing in number, whereas thickness gauges and gaschromatograph apparatus are still spreading slowly but steadily (cf. Fig. 1). Many NCSs will be in use also hereafter, though replacement must be made from old to new designs and partly from nucleonic to non-nucleonic systems.

Figure 1 does not include NCSs with sealed radioisotope sources of a small activity of 3.7 $\mathrm{MBq}$ or less that are out of regulation by the Law Concerning Prevention from Radiation Harzards due to Radioisotopes, in Japan. Although the statistics on the use of such NCSs are not clearly 


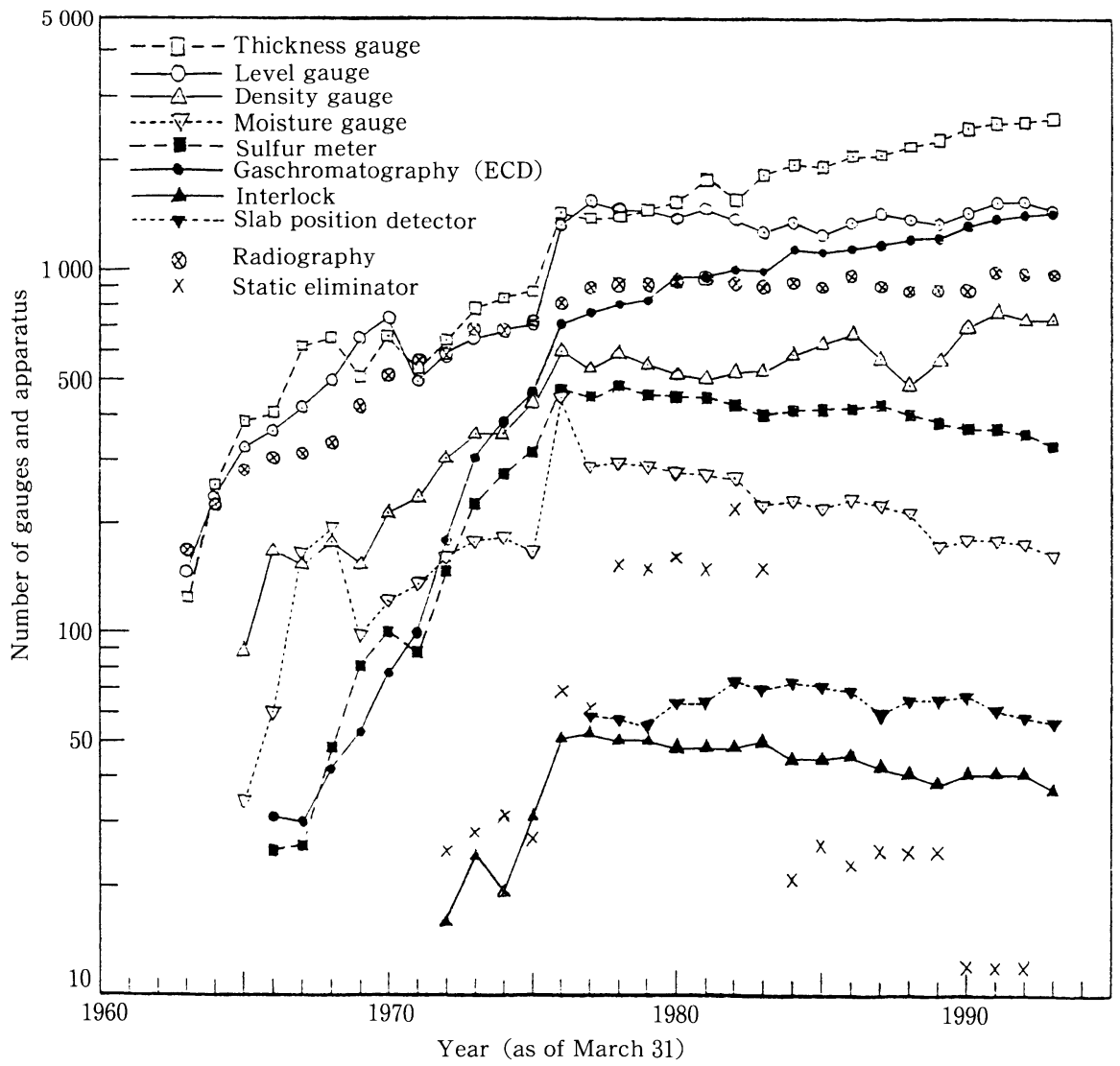

Fig. 1 Changes with the year in the number of radioisotope-equipped gauges and apparatus in use in industrial firms except research institutions.

known for the same reason, a considerable number of such instruments are in use in factories and also outdoor fields, including portable level gauges for extinguishers etc., density gauges and soil compaction gauges in the civil engineering field, and airborne-dust monitors for environmental pollution control.

Recent developments are focussed on more sophisticated techniques and advanced systems for measuring multi-dimensional or multi-component variables, for instance, on the one hand, whereas rather simple and unique applications are also attempted on the other hand.

Descriptions are given below in the present paper, in particular, on typical examples of NCSs the diffusion of which has been greatly influenced by social conditions, governmental control, authorization of techniques, competition with nonnucleonic techniques, etc. Some examples of new NCSs recently developed are also described.

\section{Changes in the Number of NCSs}

\section{$2 \cdot 1$ Social demand and legal compulsion - Sulfur meter, airborne-dust monitor, and gaschromatograph apparatus}

The rapid spread of sulfur meters described previously was obviously based upon the increase in the air pollution with $\mathrm{SO}_{2}$ generated from oil burnt in power stations, automobiles, etc. However, the rapid spread has probably never 
been effected without legal regulation of the environmental pollution. Because oil users themselves did not need to use sulfur meters. The sulfur meters with radioisotope sources are now employed on line at oil refineries and power stations to control sulfur concentrations mainly in crude oil.

Airborne-dust moniters ${ }^{2}$ for measuring the concentration of particulates in air are a more typical example of the radioisotope-applied instruments which have spread nation-wide under the direction of the government. Two methods were specified in the notification by the Environment Agency in 1981 for measuring the mass concentration of airborne particulates : one was this nucleonic method and the other non-nucleonic (piezo-electric balance). The former has prevailed much more than the latter because of its suitability to continuous measurements due to almost troubleless operation and quick maintenance capability. Nearly 1500 monitors of the nucleonic method are in routine use for continual observation of the air pollution at environmental air monitoring stations in all districts of the country. The nucleonic method is very simple, utilizing the attenuation of soft beta rays from ${ }^{147} \mathrm{Pm}$ or ${ }^{14} \mathrm{C}$ of a low activity less than $3.7 \mathrm{MBq}$ by airborne particulates collected on a roll filter paper. Various types of the monitors of somewhat different designs such as shown in Fig. 2 are supplied by several manufacturers.

The case of gaschromatograph apparatus with ECD also may be included in the same category as described above. They are now indispensable for trace analysis of several toxic substances in the environment, specified by the governmental law or standards (Japanese Industrial Standards): $e$. g., chloric agricultural chemicals, organic mercury compounds, trihalomethane, etc. The total
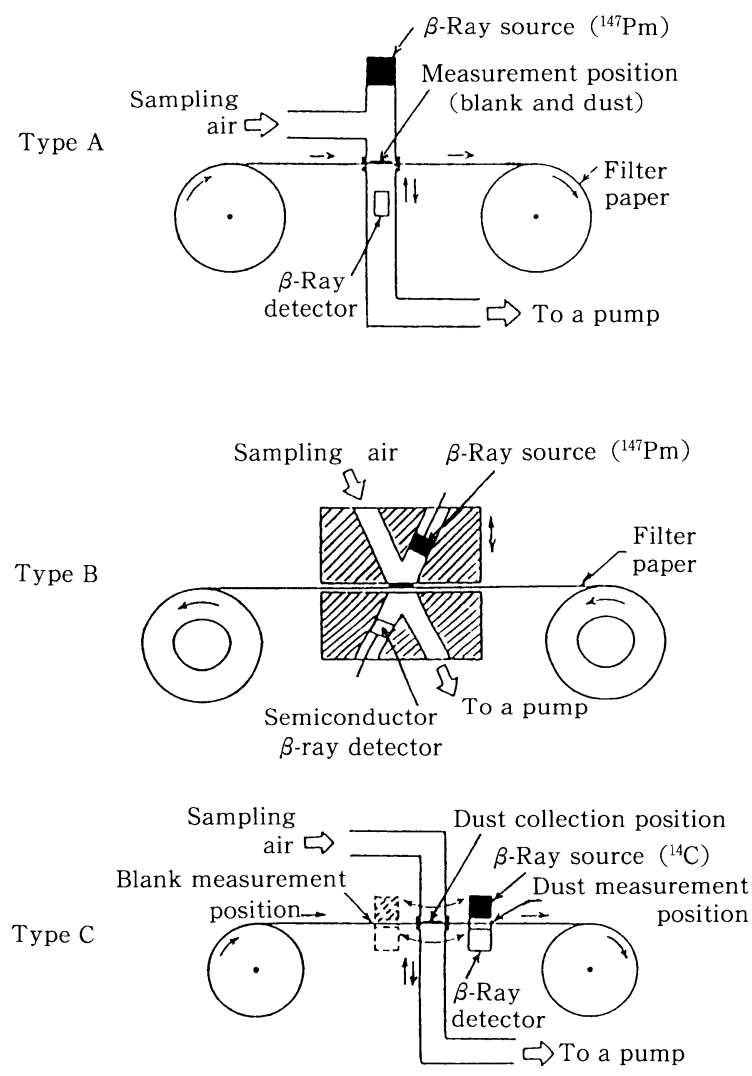

Fig. 2 Schematic drawings of airborne-dust monitors. Types $\mathrm{A}$ and $\mathrm{B}$ : Measurement is carried out while dust is being collected. Type $\mathrm{C}$ : Measurement is made before and after dust collection by moving a source-detector set from the left to the right measurement position.

number of the apparatus in all the fields is 5814 , of which 1456 are used in industrial firms except attached research institutions, as of March 31, 1993. In this connection, the gaschromatograph apparatus that meet a definite condition became to be able to use under relatively mild legal regulation since 1981: the apparatus using ${ }^{63} \mathrm{Ni}$ with a design approved and a structure certified by the government can be used, for instance, by reporting the use of it instead of obtaining permission. 
2.2 Standardization and authorization Soil compaction gauge

A surface-type soil compaction gauge ${ }^{3)}$ consisting of a neutron moisture gauge and a gamma-ray density gauge has considerably spread after the middle of the 1970's in the civil engineering field. About 500 sets of the gauges are estimated to have spread in the actual works. The conditions of the spread had been arranged by the standardization and authorization of the technique over a period of many years, described as follows:

1974 - "Handling Manual for Surface Type Density Gauge and Moisture Gauge" was published by the Japanese Society of Soil Mechanics and Foundation Engineering (JSSMFE),

1983 - JSSMFE established a standard, i.e., "Standard Measurement Method of Soil Density and Moisture Content with Radioisotopes (JSF Standard T3683T),

1985 - The method using the radioisotope density-moisture gauge was adopted by the Japan Highway Public Corporation (Nihon Doro Kodan) as the standard method for controlling the degree of compaction of embankments in situ in road construction.

Technical improvement to guarantee the accuracy in measurement was also an important factor of the success described above. Transmission geometries shown in Fig. 3 were adopted for both the fastneutron and gamma-ray measurements in the compaction gauge. This arrangement offers the advantages of a clearly defined measuring volume and less influence of coarse pebblestones.

Additionally, the use of small activity sources less than $3.7 \mathrm{MBq}\left({ }^{252} \mathrm{Cf}\right.$ and $\left.{ }^{60} \mathrm{Co}\right)$ was doubtlessly another necessary condition for the spread in the civil engineering field.
$2 \cdot 3$ Selection between nucleonic and nonnucleonic techniques-Level gauge, refractory wear monitor, and oxygen analyzer

A variety of NCSs have been tried to develop to use in industry since the beginning of the history of NCS application. In general, however, only NCSs satisfying any one or two of the following conditions have survived up to the present:

(1) No means other than nucleonic techniques,

(2) Evident advantage over non-nucleonic techniques,

(3) Strong necessity overcoming a relatively high cost of NCS and management problems in the use of radioisotopes and radiation.

Fegure 1 already mentioned displays also results of such selection in respective kinds of gauges and apparatus. In further detail, as typical examples which satisfy the above conditions in a certain degree, level gauges at glass fusion furnaces and coke quenching ovens, gamma-switches for detecting the existence of a thick steel plate in a heating furnace having a bad atmosphere with steam etc. (slab position detector) may be il-

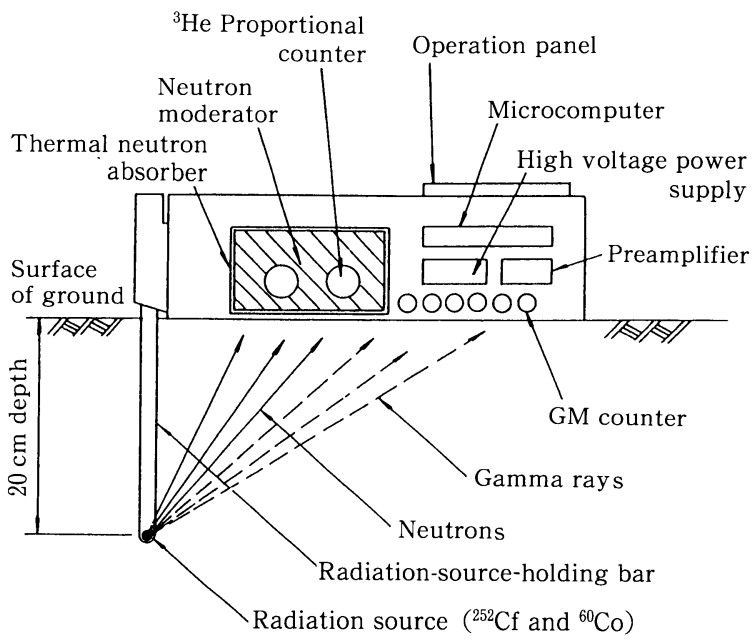

Fig. 3 Schematic drawing of a typical soil compaction gauge adopted by the Japan Highway Public Corporation. 
lustrated.

On the other hand, multi-point level gauges with plural detectors and refractory wear monitors with ${ }^{60} \mathrm{Co}$ gamma-ray sources embedded in blast furnaces are examples of the techniques which were used at one time or for some years, but later on, gradually disappeared. For monitoring of wear of the furnace walls, a new technique with thermocouples is now employed.

A rapid activation analysis technique with a 14 $\mathrm{MeV}$-neutron generator was introduced for use in the determination of trace amounts of oxygen in molton steel at ironworks in the late 1960's. However, it retired when a non-nucleonic technique using an oxygen concentration cell (oxygen probe) came to be available which can analyze free oxygen selectively.

2.4 Differencs depending on radioisotope sources - Beta-ray thickness gauge and gamma (or beta)-ray density gauge

Although some kinds of NCSs are still spread-

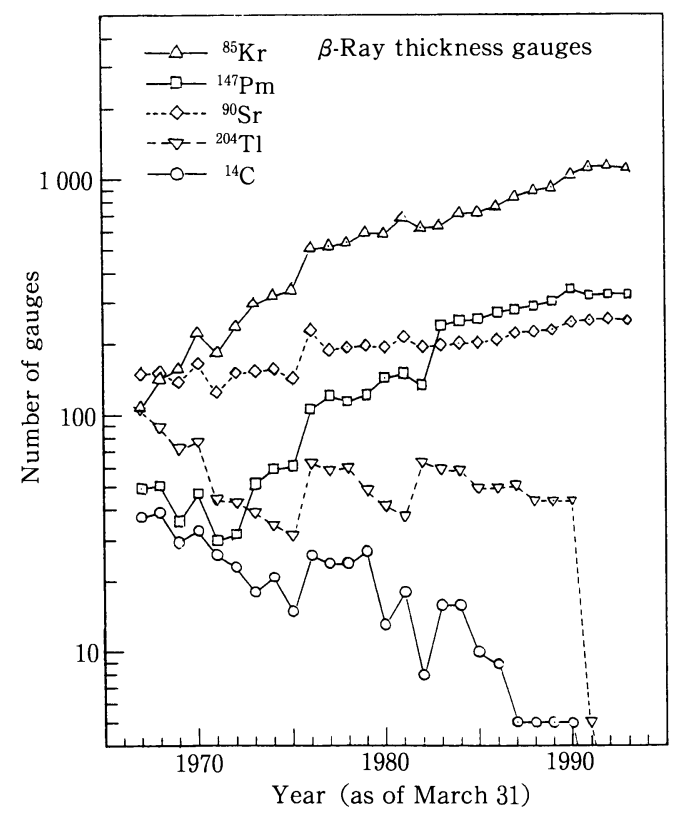

Fig. 4 Changes with the year in the number of $\beta$-ray thickness gauges with different radioisotope sources. ing, some others are nearly saturated or being diminished in number, as mentioned previously. Interesting tendencies are noticed when the changes with year in the number of different radioisotopes used in each kind of NCS are investigated.

For instance, the numbers of ${ }^{85} \mathrm{Kr}$ and ${ }^{147} \mathrm{Pm}$ beta-ray sources in thickness gauges increased remarkably in the past 20 years, whereas the number of ${ }^{14} \mathrm{C}$ beta-ray sources decreased significantly in the same period ( $c f$. Fig. 4). The reason of the decrease in ${ }^{14} \mathrm{C}$ sources is considered mainly due to a problem of instability in the sealed sources with high activities.

In density gauges, a low energy gamma-ray source of ${ }^{241} \mathrm{Am}$ shows a rapid increase in the past 10 years, whereas a high energy gamma-ray source of ${ }^{137} \mathrm{Cs}$ is gradually decreasing (cf. Fig. 5). The density gauges with ${ }^{241} \mathrm{Am}$ (gamma), ${ }^{85} \mathrm{Kr}$ (beta), and ${ }^{90} \mathrm{Sr}$ (beta) are employed as oil density gauges in airplanes imported.

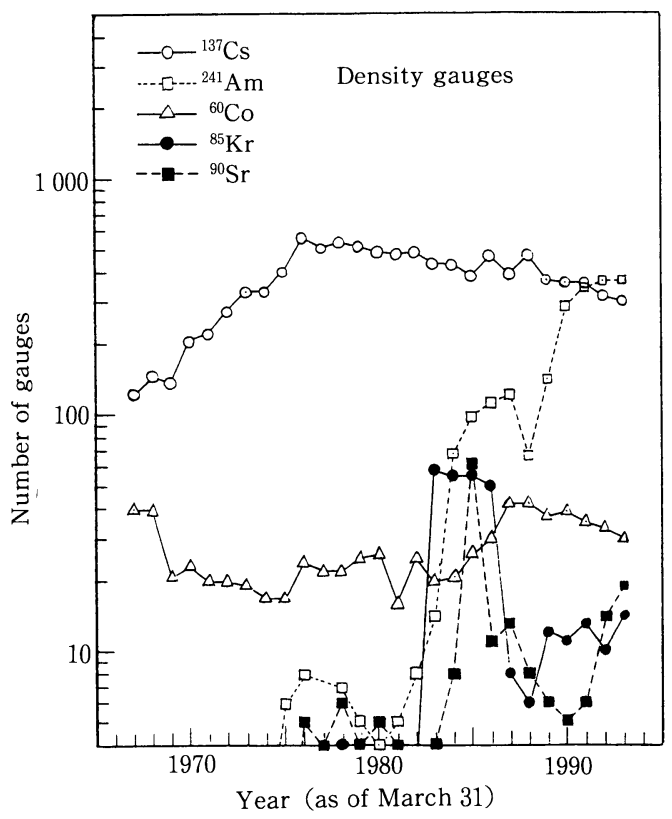

Fig. 5 Changes with the year in the number of density gauges with different radioisotope sources. 
3. Some Recent Developments of NCSs

$3 \cdot 1$ Thickness gauge of thin layer plastic sandwiched with steel plates

A new technique has been recently developed for measuring the thickness of a thin layer of $30-200 \mu \mathrm{m}$ thick plastic sandwiched with two sheets of steel plates of $0.6-4.2 \mathrm{~mm}$ in total thickness, in cooperation of the Institute of Radiation Measurements, the Japan Atomic Energy Research Institute, and the Kobe Steel, Ltd. The sandwiched steel plate is employed as a new complex steel plate with suppressed vibration and reduced noise in some portions of buildings, for instance, and is expected to use at a bottom part of automobile engines. For quality control of the complex steel plate in its production process, it is important to measure the thickness of plastic and its homogeneity. However, there was so far no nondestructive measurement technique.

To obtain a sufficient sensitivity in the measurement, a source-sample-detector arrangement and its surrounding structure were specially devised, where multiple scattering of neutrons and efficient generation of slowed-down neutrons from the plastic layer of a sample were utilized.

Figure 6 shows an example of the concept design of a prototype thickness gauge for this purpose. Two iron blocks as fast-neutron reflectors are placed on both the upper and lower sides of a ${ }^{252} \mathrm{Cf}$ neutron source with a small gap. A thin polyethylene sheet ( $3-4 \mathrm{~mm}$ thick) as a neutron moderator is plated on one side of the surface of the iron blocks in the gap. A ${ }^{3} \mathrm{He}$ proportional counter is located close to the ${ }^{252} \mathrm{Cf}$ source. A sample to be measured (about $1000 \mathrm{~mm}$ wide) is inserted into the gap. The outermost parts surrounding the iron blocks are radiation shields consisting of polyethylene containing boron. Slow-neutron absorbers are placed between the

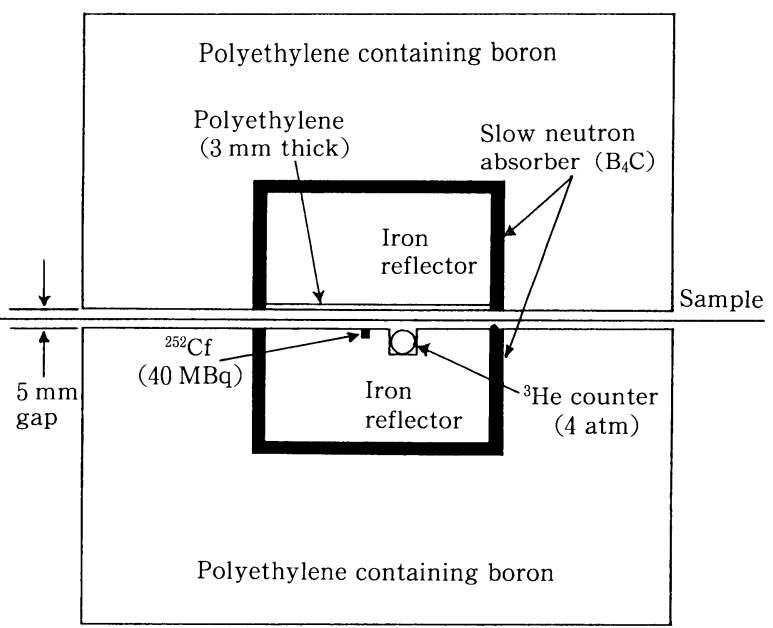

Fig. 6 Vertical section drawing of a prototype thickness gauge for thin layer plastic sandwiched with steel plates ${ }^{4)}$.

shields and the iron reflectors to reduce the slowneutron background in the counting with the ${ }^{3} \mathrm{He}$ counter ${ }^{4}$.

In the structure described above, at first glance, the polyethylene sheet may look like an unfavorable choice that merely increases the background in the neutron counting, since its thickness is larger than one order of magnitude over that of the plastic to be measured. In practice, however, the sheet plays an important role in generating

Table 1 Performance of the thickness gauge for thin layer plastic sandwiched with steel plates ${ }^{4)}$

\begin{tabular}{ll}
\hline $\begin{array}{l}\text { Range of } \\
\text { measurement }\end{array}$ & $\begin{array}{l}30-200 \mu \mathrm{mt} \text { plastics } \\
(0.3-2.1 \mathrm{mmt} \times 2 \text { steel plates) }\end{array}$ \\
\hline $\begin{array}{l}\text { Precision of } \\
\text { measurement }\end{array}$ & $\begin{array}{l}\text { Statistical }(1 \sigma): c a .5 \mu \mathrm{mt} / 1 \mathrm{~min} \\
\text { Instrumental }:<7.7 \mu \mathrm{mt}\end{array}$ \\
\hline $\begin{array}{l}\text { Slope of } \\
\text { calibration line }\end{array}$ & $c a .0 .40 \% / 10 \mu \mathrm{mt}$ plastics \\
\hline Effective & $15 \mathrm{~cm} \times 16 \mathrm{~cm}$ \\
measuring area & $(90 \%$ count-saturation widths) \\
\hline Radiation & $6 \mu \mathrm{Sv} / \mathrm{h}$ at a diatance of \\
leakage & $20 \mathrm{~cm}$ (upper side) or \\
& $\begin{array}{l}60 \mathrm{~cm} \text { (left side) } \\
\text { from each surface }\end{array}$
\end{tabular}


thermal neutrons efficiently from the plastic to be measured owing to multiple reflection of neutrons through the sheet and sample in the gap with the aid of iron reflectors. Details will be explained elsewhere.

With the design of Fig. 6 using a ${ }^{252} \mathrm{Cf}$ source of $40 \mathrm{MBq}$, the performance shown in Table 1 can be realized ${ }^{4}$. The prototype thickness gauge will be used for an off-line test in an actual production process before long.

3.2 Water content measurement in fresh concrete for evaluation of the final quality of concrete

The content ratio of water to cement in fresh concrete strongly affects not only its workability but also the final quality such as compressive strength, durability, etc. of concrete solidified. The Japan Highway Public Corporation has tried to develop a rapid method of measuring the water content in fresh concrete with the intention of evaluating the final quality of concrete ${ }^{5), 6)}$.

The method of the measurement is based on a simple technique of fast-neutron transmission, as shown in Fig. 7, which is similar to that used in the soil compaction gauge adopted by the same corporation (cf. $2 \cdot 2$ and Fig. 3). The sample container is just the same one as used for the air content test of fresh concrete. Using a ${ }^{252} \mathrm{Cf}$ neu- tron source of $3.7 \mathrm{MBq}$ that is free from legal regulation, the water content per unit volume of fresh concrete is determined in five minutes.

Corrections were made for ignition loss (chemically combined water) of aggregate and ignition residue (components other than total water) in fresh concrete on the neutron count, and for the moisture absorbed in aggregate on the total water content. Figure $8^{6}$ shows a result of the measure-

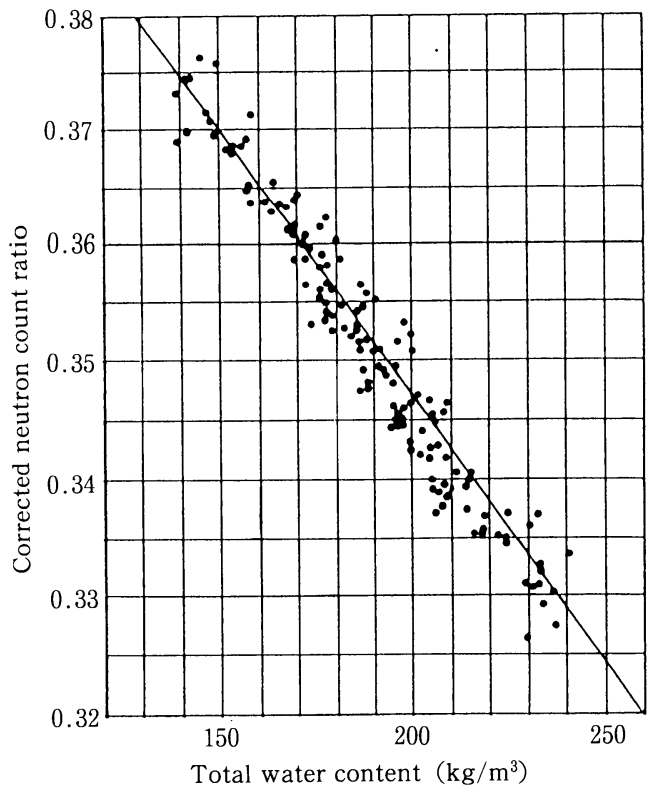

Fig. 8 Result of laboratory test of water content measurement in fresh concrete ${ }^{6)}$.

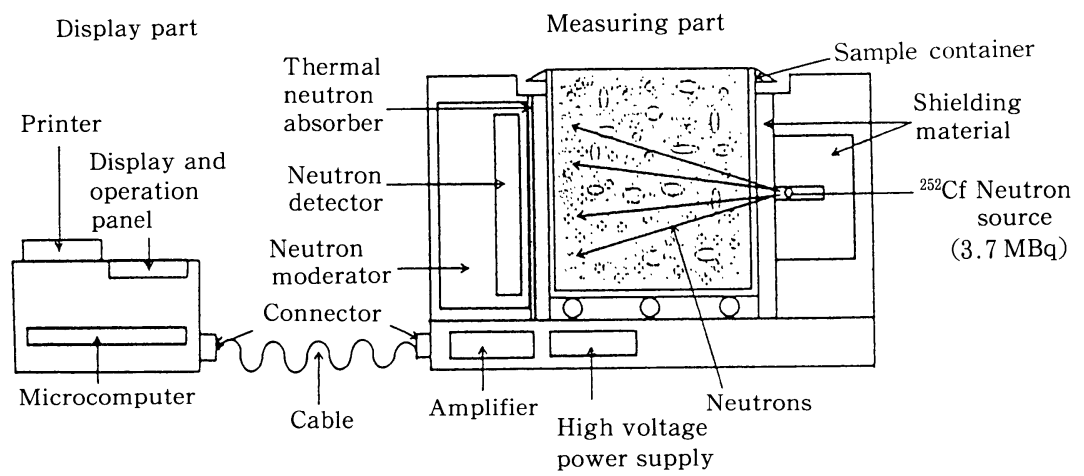

Fig. 7 Measuring instrument for the water content per unit volume of fresh concrete ${ }^{5), 6)}$. 
ment in a laboratory, illustrating a good correlation between the corrected neutron counts (relative values against a standard sample) and the total water contents (including moisture absorbed in aggregate) in fresh concrete samples. Also in field experiments, appreciably good results were obtaind in the measurement of the water content.

However, this rapid method was not adopted in practical use, because (1) good correlation was not found between the values of the compressive strength finally obtained by the rapid method and the conventional method requiring 28 days, and (2) results of the measurement could not be utilized to control something on actual spots of construction $^{7)}$.

3.3 Automated systems for compaction inspection in embankments and for pavement construction

An inspection robot $^{8)}$ was fabricated which can move freely on the surface of land to manage the quality of embankments in road construction etc. quickly in real time without manual operation, in a joint research $(1985-1987)$ by the Public Works Research Institute of the Ministry of Construction and the Mitsui Construction Co., Ltd. A newly designed density and moisture gauge, in which a backscattering geometry was employed for both gamma rays from ${ }^{60} \mathrm{Co}(2.3 \mathrm{MBq})$ and neutrons from ${ }^{252} \mathrm{Cf}(1.1 \mathrm{MBq})$, was mounted in the robot. The degree of soil compaction was measured continuously while moving or stopping with correction for changes of the gap between the bottom of the robot and the surface of land (using a non-nucleonic gap sensor). The basic properties of the robot as an automated system for continuous measurement of compaction in embankments was confirmed by the research, though the robot itself was not put to practical use.

The aim of the research was to cope with the shortage of man power well-trained and the need of advanced technology in the civil engineering, including the improvement of safety, efficiency, and accuracy of inspection in construction of road etc.

For a similar purpose, a five year project of the Ministry of Construction was started in 1990 for development of an automated pavement construction system, in which a density and moisture gauge of the same type as used in the robot described above is employed as a sensor for measuring the compaction degree of a surface layer (asphalt) and road beds (aggregate) in pavement construction $^{9)}$. In an automatic compactioncontrolling roller car designed on the basis of field experiments, as shown in Fig. 9, the compaction gauge with small wheels is connected to the forepart of the car having a vibrationless front roller. The measurement with the gauge is performed immediately after rolling while the car is moving

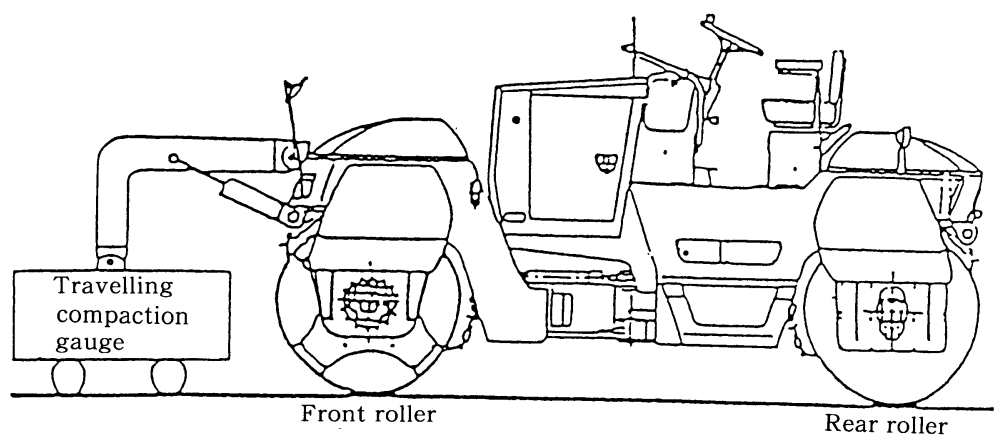

Fig. 9 Automatic compaction-controlling roller car designed for automated pavement construction ${ }^{9)}$. 
backward, and the feedback of measurement result is made to the vibration power of a rear roller, controlling automatically the compaction power of the car. Since the position of the car is measured by means of a rotary encoder combined with a vibrating gyro, a map of resulting distribution of the compaction degree is displayed on a monitor. Development of the system including software is being continued for practical use of the car.

3.4 Gamma-ray backscatter density gauge with dual source-detector spacing for a sintering plant

In a sintering plant of iron works, it has come to be recognized that measurement and control of the state of raw materials loaded on a conveyor are important to improve the yield of sintered ore in the plant. In particular, the distribution of bulk density at a surface region of the materials is considered to be an important factor influencing the condition of sintering. A gamma-ray backscattering type density gauge can be applied to the measurement, if the distance between the gauge and the surface of the materials is measured to
Measurement spot

Operation room

Gauge and an object of measurement

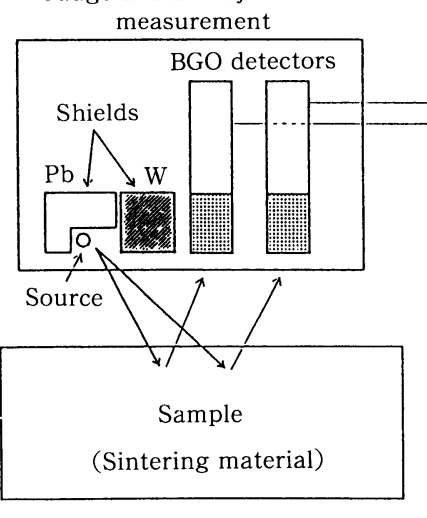

Electronic and computing instruments
Fig. 10 Schematic diagram of a density gauge with dual source-detector spacing for a sintering plant ${ }^{11)}$. correct for its variation by some means. However, there was no conventional distance sensor suited to this application.

Shirakawa et al. ${ }^{10)-12)}$ have developed a gammaray density gauge consisting of a single gammaray source and two gamma-ray detectors in a backscattering geometry, measuring both the surface density and the distance simultaneously. The total system is schematically shown in Fig. 10. The two detectors arranged with appropriately different spacings from the source have different calibration characteristics for the density and the distance each other. In the case where the ranges of variation of both the density and the distance are not wide, each detector gives output of an approximately linear function regarding the density and the distance, making it easy to solve their simultaneous equations.

In practice (off-line test), the calibration curves shown in Fig. 11 were obtained using a ${ }^{137} \mathrm{Cs}$ gamma-ray source of $3.7 \mathrm{MBq}$, two BGO (50

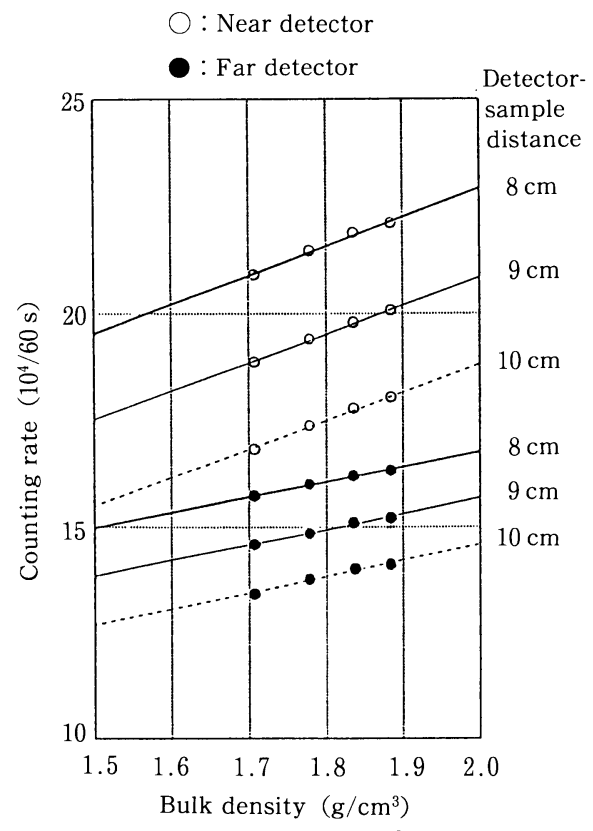

Fig. 11 Calibration curves for gamma-ray counts of two detectors with re spect to the density and distance of samples, obtained with the gauge of Fig. $10^{11)}$. 
$\mathrm{mm} \phi \times 50 \mathrm{mmt})$ scintillation detectors, and standard samples specially prepared by concrete. Solving the simultaneous equations provided from the data of Fig. 11, the deviations of determined values of the density from the true ones were found to be within $\pm 0.02 \mathrm{~g} / \mathrm{cm}^{3}$ in the range of the data of Fig. 11. In a wider range of $1.5-2.0$ $\mathrm{g} / \mathrm{cm}^{3}$ in the density, the required accuracy of the density, $\pm 0.05 \mathrm{~g} / \mathrm{cm}^{3}$, is guaranteed with the measurement for $60 \mathrm{~s}^{12}$.

The newly developed gauge was installed at a position between the raw material hopper and the ignition furnace of Kimitsu No. 3 sintering plant of the Nippon Steel Corporation, as shown in Fig. 12, in 1992. Since then, it is now smoothly in routine use, contributing to control of the density distribution of loaded raw materials.

\section{Conclusions}

Various kinds of NCSs have been developed and some of them have been in practical use, but some others were not put to use. Only selected ones of NCSs were widely diffused which met just needs in industry or public demands including legal compulsion and other technical, economical, and/or social conditions. The standardization of a technique in a special field of industry and its adoption by a semigovernmental organization were also a decisive factor of its spread.

It seems that the total number of NCSs with a source exceeding $3.7 \mathrm{MBq}$ is nearly in a state of saturation in recent years. The number in all the fields is 13850 , of which 8991 are in industrial firms (except attached research institutions), as of March 31, 1993. On the other hand, the total number of the instruments with a source of 3.7 $\mathrm{MBq}$ or less activity is estimated to be about 5000 and is still increasing.

By using such small activity sources, as are seen in the last three examples of recent developments (cf. $3 \cdot 2,3 \cdot 3,3 \cdot 4)$, unique developments and applications will be furthermore advanced, where-

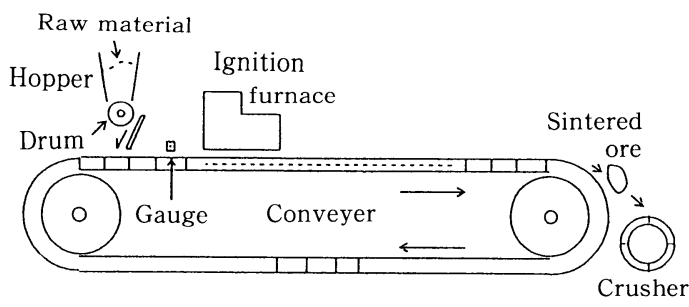

(a) Sintering machine with the gauge

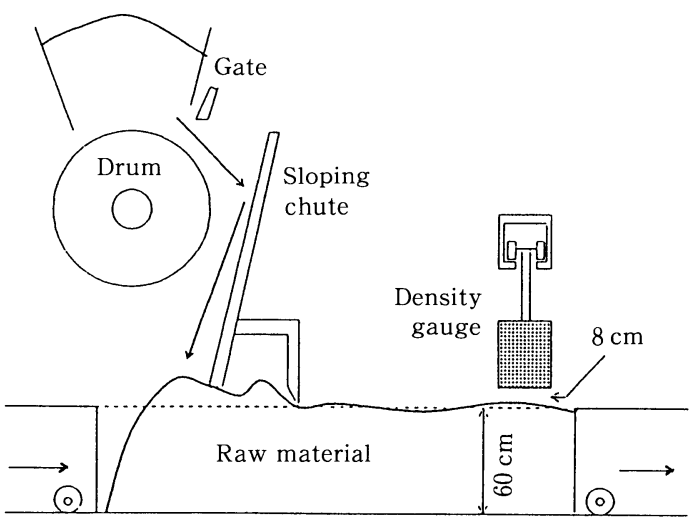

(b) Expanded view of the spot of density gauge installation

Fig. 12 Installation of the density gauge of Fig. 10 at a sintering plant ${ }^{11)}$.

as more sophisticated techniques using intense radiation beams, including the use of X-ray generators, particle accelerators, and neutron generators, are also considered to be developed, though detailed discussion of them was not made in this paper.

\section{References}

1) Tominaga, H. : Radioisotopes, 33, 100-108 (1984) (in English)

2) Ise, H. : Proceedings of 21st Japan Conf. on Radiation and Radioisotopes, B140, Japan Atomic Industrial Forum, Inc., Tokyo (1994)

3) Yamamoto, T. (Kajima Technical Research Institute, Kajima Corporation) : Private communication (1990)

4) Tominaga, H., Tachikawa, N., Ishikawa, I., Azuma, M. and Arai, A. : Abstract papers of 31st Annual Meeting on Radioisotopes in the Physical Sciences and Industries, p. 94, Japan Radioisotope Association, Tokyo (1994) 
5) Yamamoto, T., Fujioka, M. and Mizuno, T. : Nihon Doro Kodan Research Institute Report, 28, 63-71 (1991)

6) Nihon Doro Kodan : Leaflet "Rapid evaluation of concrete quality in fresh concrete"

7) Ando, H. (Research Institute, Nihon Doro Kodan) : Private communication (1994)

8) Tanaka, M. and Takada, T. : Proceedings of 20th Japan Conf. on Radiation and Radioisotopes, pp. 331-340, Japan Atomic Industrial Forum, Inc., Tokyo (1991)

9) Nakamura, T., Kiriyama, T. and Mori, S. :
Doboku Gijutsu Shiryo, 35, (9), 22-27 (1993)

10) Shirakawa, Y., Sekiya, M., Takahashi, T. and Amano, H. : Abstract papers of 29th annual Meeting on Radioisotopes in the Physical Sciences and Industries, p. 39, Japan Radioisotope Association, Tokyo (1992)

11) Shirakawa, Y. and Amano, H. : Soc. Instrum. Contr. Engineers, 29, (5), 504-511 (1993)

12) Shirakawa, Y. : Doctorial thesis, "A study on a density gauge based on gamma-ray scattering" (1993) 